Ps

Bibliography of Indonesian Peoples and Cultures By Raymond Kennedy. (Yale Anthropological Studies, Vol. 4.) Pp. 212. (New Haven, Conn.: Yale University Press; London: Oxford University Press, 1945.) 16s. 6d. net.

Tr HIS bibliography aims at giving a complete list of works refatifoto the islands of the Indian Archipelage fro rative point of view of anthropology and socc/dy mcluding archæology, linguistics, and stufieg of cculturation, but not omitting those works on a fuaphy, history, and economics which are pertine to anthropological studies in general. The bibliography is set out on a geographical basisgeneral works first, then works dealing with particular areas, the list being divided in each case into works in Dutch and those in other languages. Eight main divisions are used-Indonesia in general, Sumatra, Java, Borneo, Celebes, the Lesser Sundas, the Moluccas, and Netherlands New Guinea. There are seven maps which show the location of the places and peoples appearing in the list. The mainland of the Malayan Peninsula and also the Philippine Islands are omitted from this volume, which is published in photolitho.

The list has taken some sixteen years to compile and must be very nearly complete; nevertheless, one or two omissions are to be found, and the very paucity of these is a testimony to the completeness of the whole.

Marsden's "Memoirs of a Malayan Family" (London, 1830) should have found a place under Sumatra, and Favre's "An Account of the Wild Tribes inhabiting the Malayan Peninsula, Sumatra and a Few Neighbouring Islands, etc." (Paris, 1865) might have justifiably been included in the general Indonesian list, though it is true that Favre deals primarily with the Golden Chersonese. Where there are several editions of a book there seems to be some inconsistency as to citation-thus, only an early (1783) edition of Marsden's "History of Sumatra" is given, but only the latest (1930) edition of Hamilton's "New Account of the East Indies". It is, however, obvious that in a work of this kind perfect complete$n \in \mathbb{S S}$ is almost impossible of achievement, and an occasional omission does little to impair the value of such a thorough and meticulous bibliography.

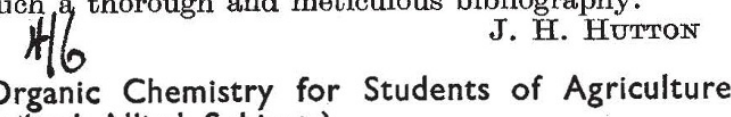

(and Allied Subjects)

By Dr. Cyril Tyler. Pp. viii + 341. (London : George Allen and Unwin, Ltd., 1946.) 15s. net.

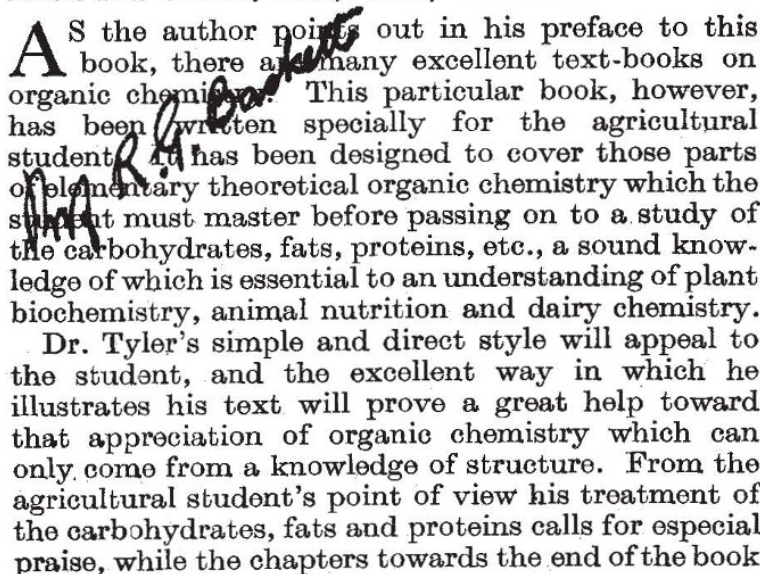

which concern vitamins, hormones, essential oils and other substances with which the agricultural student must have acquaintance are treated adequately.

The author's approach to his subject is essentially factual, and his book contains no mention of the history which lies behind our knowledge of the subject. It might be argued that the inclusion of matter of historical interest would have meant the excision of certain parts of the existing text if the book was to be sold at its present reasonable price. It is, however, difficult to make theoretical organic chemistry 'live' without some reference to its history. No doubt those whose students use this book will cover this aspect in their lectures.

The B.D.H. Book of Organic Reagents for Analytital Use

Ninth and enlarged edition. Pp. $x+196$. (London : British Drug HousegiLtd., 1946.) 4s. 6d. net.

THE apposh hev a new edition of this well1 kyfor. $18 \mathrm{kk}$ will be welcome to all analytical a d fubr chemists. Three reagents, dihydroxytaf Iric acid osazone for calcium, phenylthiohydantoic ad id for cobalt, and phenylaminobenzene-azo-benzene sulphonic acid for magnesium, have been omitted as a result of experience obtained since the last edition. Four new reagents are included for the first time triketohydrindene hydrate for the determination of free amino-acids, 8-hydroxyquinaldine for the estima. tion of zinc, benzylisothiourea hydrochloride for the characterization of sulphonic acids, and $p$-nitrobenzene-azo-orcinol for the determination of beryllium. In addition, the whole text has been thoroughly revised and the general level of excellence and accuracy of the previous editions well maintained.

\section{Rapid Tomato Ripening}

For Nurseryman and Amateur, with Notes on Possible Application to other Fruit. By L. D. Hills and E. H. Haywood. Pp. $143+12$ plates. (London : Faber and Faber, Ltd., 1946.) 8s. 6d. net.

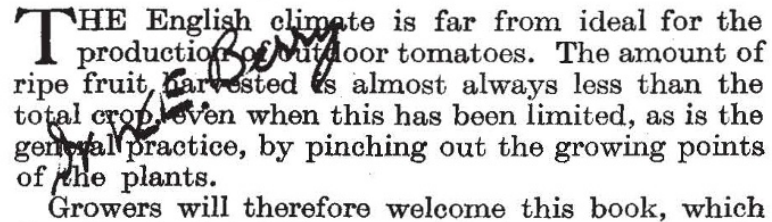
describes in detail the use of ethylene or coal gas to ripen the green fruit after picking. This is the first practical manual on the subject, and as such deserves wide circulation among tomato growers. It describes the construction and operation of ripening boxes and chambers suitable for handling a few pounds or several tons of fruit. The book, which is based upon the authors' own experience, is written in a free-andeasy style, and though the frequent parentheses occasionally obscure the sense, the practical directions will be easily followed by the non-scientific reader. The authors are less fortunate in their attempts at scientific explanations; thus on p. 41 we read "The thermometer, by the expanding of the mercury molecules in which temperatures are measured ...", and on p. 131 we are told that "The formula of ethylene is $\mathrm{C}_{2} \mathrm{H}_{5} \mathrm{OH}$; that of acetone or amyl acetate ... is $\mathrm{C}_{3} \mathrm{H}_{6} \mathrm{O}^{\prime \prime}$. The book is not, however, written for men of science, and these extraordinary statements do not detract from its undoubted value to the tomato grower. It is attractively produced and illustrated.

re Publishing Group 